mansasa

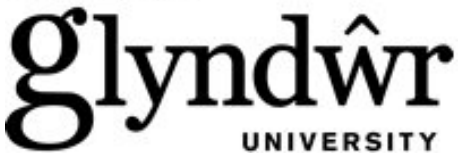

Glyndŵr University

Glyndŵr University Research Online

Social Inclusion Research Unit

Social and Community

$1-1-2006$

\title{
Volunteers, Families and Children in Need: An Evaluation of Family Friends
}

L Parrot

Julian Buchanan

Glyndwr University, julianbuchanan@gmail.com

D Williams

Follow this and additional works at: http://epubs.glyndwr.ac.uk/siru

Part of the Clinical and Medical Social Work Commons, Marriage and Family Therapy and Counseling Commons, and the Maternal and Child Health Commons

The definitive version of this article is available at www.blackwell-synergy.com (C) 2009 Blackwell Publishing Ltd

\section{Recommended Citation}

Parrott, L., Buchanan, J., \& Williams, D.(2006) 'Volunteers, Families and Children in Need: An Evaluation of Family Friends'. Child \& Family Social Work, 11(2), 147-155

This Article is brought to you for free and open access by the Social and Community at Glyndŵr University Research Online. It has been accepted for inclusion in Social Inclusion Research Unit by an authorized administrator of Glyndŵr University Research Online. For more information, please 


\title{
Volunteers, Families and Children in Need: An Evaluation of Family Friends
}

\author{
Parrott, L., Buchanan, J. \& Williams, D.
}

\begin{abstract}
This paper explores the findings from a small-scale research project (Buchanan et al 2002) that analysed the impact of Family Friends - a voluntary agency that provides support to families under stress who have children aged between 5 and 11 years. The study evaluated service users' perceptions of the support they received, specifically the significance and impact of the volunteer befrienders. The research identified that there are a proportion of families in need who fail to attract services from mainstream statutory agencies. In particular, the research identifies that the Family Friends voluntary agency makes a significant contribution to service provision by offering a friendly, non-stigmatising, caring and responsive service.
\end{abstract}

\section{Key words}

Voluntary, family support, child protection, preventative, research, welfare, service users.

\section{Introduction}

Family Friends is a voluntary organisation based in Wrexham, Wales that trains volunteers to support parents who are experiencing stress as a consequence of their children, the first group of trained volunteers starting supporting families in 1998. The volunteers provide regular support, friendship and practical help tailored to the needs of families who are experiencing difficulties, where at least one child is between the ages of five to eleven. The scheme receives referrals from any source, provided it is with the family's consent. The families that have been referred are then matched to home-visiting volunteers, who are recruited, trained and supported by the Family Friends Co-ordinator. The organisation also arranges occasional group activities, such as outings, drama workshops, sporting activities and courses for families. During school holidays it provides a family fun club. In assessing the impact of this voluntary organisation the research team wanted to ensure 'that the research in which they are engaged contributes to empowering service users, to promoting their welfare and to improving their access to economic and social resources' (BASW, 2002, p.14).

\section{The Context of Family Support}

Government policy has sought to develop direct initiatives for family support. These include projects such as Sure Start - a programme to support 0 to 3 year olds and their families in deprived areas; a National Childcare Strategy to ensure affordable and appropriate child care; the use of Lottery funding to support out of school clubs for children; and broader social support projects for families. Health Action Zones and Education Action Zones have also been established which seek to target resources to assist the poorest families and carers to enable better health and education outcomes.

The promotion of family support assumes a shared understanding of what is meant by 'family', and it should be acknowledged that this is a contested area. Indeed, some notions of family could be prohibitive and deter some people 'in need' from seeking help. For example, more restrictive definitions of family which promote the centrality of marriage, may lead to some parents and carers feeling unable to access such provision. It could also result in children who belong to a non-traditional family network feeling that they are second best. Thus in order to provide 'family' support, a broad and inclusive definition is needed to enable both service providers and service users, to work together effectively. However, finding consensus on a definition of 'family support' can be difficult (Armstrong and Hill 2001). Arguably any definition needs to involve both a wide 
range of activities and arrangements, to encompass the diversity of what is lived out as 'family'; and to satisfy the concepts of family that are embraced by a wide range of different service providers such as the state and the voluntary and independent sector. In addition to the contested notion of family there is uncertainty concerning the definition of 'need' and the criteria for determining precisely who should receive 'family support'. It could be argued that family support is something which all parents should be able to access. It appears however, politicians and statutory agencies increasingly perceive such support should be reserved for those families most at risk of losing their children to the statutory care system. While this rationing of family support has been promoted by the Personal Social Services (PSS) it has also led to increasing unease in the way that PSS have responded to the Children Act 1989 resulting in a narrowing of provision to support only 'at risk' families.

Linking family support with children at risk is problematic, as Colton et al (1995) argue, the fewer the number of recipients of family support services and the more narrow the focus, the more stigmatising the service can become. This crisis intervention strategy to prevent impending state intervention could lead to prospective users of such services being highly resistant to receiving the help they need. Family support could easily be seen as a resource for 'problem' children and/or 'problem' families. As the focus of the PSS child care services has shifted towards an almost exclusive concern with child protection issues, then social workers are increasingly less able, or indeed equipped, to offer more supportive preventative service (Morris \&Shepherd 2000). Inevitably, the PSS must rely upon the voluntary sector as a means of filling this gap. As Tunstill (1997) observes, the PSS has retreated from providing family support services directly, and have increasingly used the voluntary sector to meet this shortfall in services. Concern regarding this shift, has led to government attempts to redress the balance (Howarth 2001), known as the 'refocusing debate', this realignment is an attempt to refocus the PSS towards preventative work by directly supporting families at risk. The refocusing debate seeks to provide a broader basis for working in partnership with other statutory and voluntary bodies to reduce the impact of poverty and social exclusion upon disadvantaged families. The White Paper 'Modernising Social Services' (Department of Health 1998) underpins this push towards preventative work, for example, in Wales it resulted in the 'Children First' strategy which sets out a national childcare framework in which the PSS is required to meet defined targets for service delivery, within which measures to improve family support figure strongly.

In policy terms then preventative care for family and children's services within the PSS are now a much greater priority. The role of the PSS is however, just one part of a wider government policy focus upon the family, which involves a variety of agencies requiring a carefully co-ordinated partnership response. The Labour government sees the voluntary sector as a vital source of family support, working in partnership with the local authority. The Home Start programme which provides trained volunteers offering regular support, friendship and practical help to young families under stress, is a good model of this partnership in action (Frost \& Johnson 2000). In recent years the government and local authorities have encouraged a large number of voluntary sector initiatives, as these projects have been developed there has been little investigation into their effectiveness.

\section{Studies into family support}

Although the number of studies evaluating family support is relatively small (McGrath 2001, Gray 2002, Statham \& Holtermann 2004), some tentative conclusions can be drawn. These qualitative studies suggest families that are struggling to cope with extreme physical, emotional and social demands generally have little or no support. These families value practical care and emotional support very highly (see Wardle et al. 1999). It is clear from these studies that voluntary groups who support families can have a significant impact. This is reflected in the distinction made between voluntary workers who are perceived as having more time and commitment to support families, compared to professional social workers, who are generally viewed with a degree of suspicion and hostility. This suspicion is likely to increase if the PSS and their social workers see child protection work as their primary focus at the expense of preventative support for families in need. If family support is to be effective, the investment of 'emotional labour' by the staff has to be valued by the organisation and appropriate workload relief given to enable social workers to 
make this investment of time. At present this seems to be more effectively achieved by voluntary sector workers than statutory staff, however, the involvement of voluntary groups and providers is not unproblematic or without tensions. For example, the emotional labour invested by support workers must sometimes be balanced by the requirement to work alongside statutory services when concerns arise regarding child protection. Thus if family support is to be effective it has to balance the needs and requirements of families with the recognition that those families may sometimes require statutory intervention. How voluntary providers manage tension between voluntary support and state intervention will be crucial for their success. While they do not want to become an arm of the statutory services and potentially risk alienating families and breaking down the trust they have developed, they must however, ensure that families and children do receive appropriate protection as and when required.

The research on Family Friends is a small scale pilot study designed to focus on the experience of the people who regularly use the service; recording the parents and carer's experiences and giving them a voice. It is not intended to make comparisons with other family support initiatives, nor with similar families not receiving such support. It is hoped that as part of an ongoing research programme the process can be further developed to both widen the scope of the study and take into account some of the problems outlined in particular by Oakley (1998) and McDonald (1999) towards providing more evidence based results. While the research actively involves the service user and gives them a voice it does not fully address Jordan's (2002) desire to see the users of the service actively involved designing and shaping the research process.

\section{Family Friend Sample and Methods}

In developing and planning the research project it was important from the outset to acknowledge the significant role that volunteers played within the organisation and invest time in preparatory work with them. Thus, an event to meet volunteers before the field work began was arranged. This meeting served three purposes: It provided a forum for the volunteers to meet with the researchers to understand the nature and purpose of the study, answer any questions that they may have, and allay any of their concerns. It enabled the researchers to discover more about the nature of the work and the role of volunteers, which helped to inform the structure and content of the semi structure interview schedule. It also helped gain the volunteers support for the research study, to enable them to then explain the research project to families and encourage their participation.

The sample criterion was based on all families who had received a service from Family Friends within the past six months prior to the research commencing. Thirty-seven families came within this category and they were contacted and invited to participate. Seventeen agreed to participate in the research, fifteen of whom were randomly selected to participate in the study. Fourteen families actually went on to be interviewed; this included twelve women as primary carers and two men as primary carers, looking after a total of 29 children. Five of the fourteen families were lone adult households. Seven of the sample described themselves as White Welsh, six White British and one Kurdish Turk. The age of respondents ranged from 29 to 59 years, with an average age of 39 years. All respondents apart from one identified themselves as being first language English speakers, so the remaining interviews were conducted in English, though we did have a first language Welsh speaker available to join the research team if needed, and we used the services of a professional interpreter to interview the Kurdish Turk family.

The importance of ensuring that interviews could be conducted in the 'language of choice' for all is important - particularly in Wales. Bilingual provision is vital not only in terms of the research process but also for effective delivery of human services in Wales where $21 \%$ of the population speak Welsh (National Statistics, 2004). The use of the Welsh language was in the past, prohibited by many employers and public agencies in Wales (Madoc-Jones \& Buchanan 2003). This stigmatised and suppression has had a detrimental impact on Welsh speakers who have 'learnt' over the years not to use Welsh when communicating with public or official bodies. They have often been reluctant to exercise their 'right' to speak Welsh despite the 1993 Welsh Language Act which accredited the Welsh and English languages with equal status. As MadocJones \& Buchanan (2003 p.229) note; 
'The derision of the Welsh language in the UK and the difficulty in being 'accommodated' in Wales is particularly inhibiting and has been a successful deterrent, ultimately making most Welsh speakers feel uncomfortable using their own language in formal public arenas.'

In terms of the profile of the volunteers none of them were fluent Welsh speakers, thereby removing the option for families under stress to receive support through the medium of Welsh. A small number of volunteers had previously been users of the project. All the volunteers were either from White Welsh, White British, or 'White Other' backgrounds. As Lukka and Ellis (2001) note there is an under-representation of people from black and ethnic minority groups as volunteers, though there is a general under representation of people from black and ethnic minority groups living in North Wales.

Despite the fact that the three researchers were all professionally qualified social workers, the volunteers were initially reluctant to trust 'academics' in their notorious 'ivory tower'. Only after some initial discussion and reassurances was the research study fully approved and supported by the volunteers. This was because families were commonly described as being suspicious of 'professionals' particularly those from a statutory service - this is one likely explanation why some families declined to be interviewed. The volunteers had concerns about professionals 'undoing' the 'good work' they had done, illustrating the perceived and sometimes real 'social distance' between the researcher and the researched. Whitmore quotes a single parent pregnant mother involved in evaluation of a prenatal programme to illustrate what appears to be a growing divide:

"Our world is different from yours. The fear is that people always want to humiliate you, put you down... We have a different lifestyle from you. We just don't trust people the way that you do" (Whitmore 1994, p.92).

\section{The Research Process}

The researchers wanted to design an interview schedule that would encourage respondent's narrative and create a rich resource of qualitative data. However, also included within some sections was an opportunity for respondents to rate their experience using a Likert scale. This enabled the presentation of some quantitative data as requested by the agency, though this has limited value given the small sample size. The first phase of the study involved semi-structured interviews with parents or carers and careful consideration was given to the design of themes and questions. The overarching question the research set out to answer was; 'How do users of Family Friends Volunteer Support view, experience and perceive the service they receive and what difference, if any, does it make?'. The interview schedule was based on four key areas; the referral process, the co-ordinator, the volunteer help, and suggestions for ways Family Friends to improve their service.

Traditionally, there has been an emphasis on the need for the researcher to remain objective, distant and quite separate from the respondents; adopting a stance that participants should feel neither worse, nor better by participating in the research. Feminist research methodology (Oakley 1998) however challenges the mythology of 'hygienic' research that suggests personal involvement results in a dangerous bias. As Oakley (1998) stresses personal involvement 'is the condition under which people come to know each other and to admit others into their lives' (p.58). The undertaking of this research involved the respondents allowing 'us' (the researchers) into their lives and their homes. For thirteen of the fourteen interviews, participants agreed to be interviewed in their home. One participant was interviewed at the college, as she said this fitted in better with her arrangements for the day. The researchers, whilst conscious of not influencing responses, sought to interview participants in a responsive and engaging manner. In one particular case it emerged that a family had been treated inappropriately by their GP, in response the researcher made the family aware of their choices within this situation, then, with the families' permission made the Family Friends agency aware of the incident. 
The length of interview varied from thirty-five minutes to two hours, but with the majority lasting an hour. In all cases the researchers found the respondents interested in the project, welcoming and keen to share their stories. At the end of the interview participants were told of the second stage of the research, namely a 'focus group' that would be set up to bring all the respondents together to identify key themes emerging from the research and explore these issues further. This second stage of the research was conducted three months after the initial interviews took place. As Krueger \& Casey note “a focus group isn't just getting a bunch of people together to talk...it is a better way to understand how people feel or thinks about an issue, product or service " (2000, p.4). This session enabled more detailed discussion and examination of the key issues, and was valuable in providing respondents with a presentation of the initial findings. However, only three respondents attended the focus group, probably due to a number of factors including; unease at attending a new venue, difficulties travelling, child care commitments and/or a lack of incentive.

\section{Findings}

These findings reflect the views and perceptions of individual service users in this pilot study. Inevitably, they contain positive and negative experiences, likes and dislikes which have been recorded and distilled. A more comprehensive analysis and in depth study would necessitate a wider range of interviews with; referring agencies, Family Friends staff, volunteers and the children themselves.

Only one person self referred to Family Friends, the rest were referred via agencies with social work being the main agency to refer (seven families), other referrals came from Salvation Army, Autistic Society, Health Visitors and School Nurses. This is hardly surprising given that only five of the fourteen families interviewed knew about Family Friends prior to their involvement. All fourteen families said they would recommend the agency to friends or neighbours.

The reasons why families sought help varied. The majority of the families were struggling to cope with children who had disabilities or behavioural problems, often with limited financial resources, though one person was getting help to supervise difficult access/contact from an estranged husband. In some instances the help was perceived to be for the benefit of the children, while in other cases the volunteer support was aimed specifically towards the parent. Common responses were to 'help me out', 'help me cope', 'get some support', 'someone to talk to', 'keep me calm'. Comments from two families illustrate the range of support:

'problems with my ex-husband, intimidating me especially with my children, I needed a third party involved and social services weren't interested'

'the type of help I require is not covered by Social Services ... it's the type of service a lot of mums would want'

Before allocation of a volunteer the families had to be assessed by the Family Friends Coordinator to determine need and match with a suitable volunteer. This initial interpersonal communication was a crucial first point of call and likely to leave a significant impact upon families already under stress. The response from the parents was positive, especially with regard to key issues such as confidentiality, respect and understanding. One criticism was that sometimes parents/carers were not always left clear about the role and function of Family Friends and what the next stage of the process would be. The comments below from the parents speak powerfully about the isolation and struggles they had to cope with and the relief that many felt at having someone specifically to support them. They valued having someone who 'really' did listen to them, understand what was happening to them, and appreciated how it was impacting upon them. Interestingly, many saw this help as distinctly different from the type of assistance provided by statutory agencies, which they saw a controlling, intrusive or surrounded in stigma. Comments included; 
'she just came to the house and listened'

'Someone from the outside was getting involved and made me aware of what we were going through, and something good was going to come out of it. We are quite good friends with our social worker, but there is a stigma attached to social services, but with these [Family Friends] I felt more relaxed it was a positive thing'

'they were reliable not full of empty promises'

'There was help there, somebody else I could turn to... with the troubles we've had, you feel very alone ... nice to think there is somebody outside the family to help'

It appears that many parents felt they did not have much influence over the selection of the volunteer they received. This may be a decision that is best left with the coordinator to manage, but it was clear that some parents would like more involvement. Issues such as age, experience and lifestyle of the volunteer clearly mattered to some families. However, some families who initially felt mismatched were pleasantly surprised.

'[She looked like] Mrs Pepperpot, carpet slippers and grey hair. But that was just a pre judgement when we got to know her she was great ...

'She is like me.. she understands and listens to what I have to say, she's dead chatty, she is down to earth, I prefer them to have the experience with kids I am having...dress is important'

'Excellent she smokes'

Most of the families received weekly support from their volunteer some fortnightly, but many felt they could have benefited from even more support

"I would like it to be more often ... but I am very grateful for what I have, they are only volunteers, they are not paid for what they do'

'Family Friends were trying to end the volunteer with us and I felt we still needed it so we only get one once a fortnight now ... we were told by Social Services we would get a lot more help but it never happened'

The initial concerns and apprehension of the parent when meeting the volunteer cannot be underestimated. There is a lot at stake and the families in need may have high hopes that the volunteer will be able to make a significant difference. Most families received weekly support, but almost inevitably many wished they could have more assistance. The difficulty was differentiating between what families needed as opposed to what families wanted. Family Friends have a scarce resource and inevitably have to prioritise to ensure a service is provided to the families who most need it. The support offered by volunteers could be divided into two main areas, the provision of short term respite care of children (which accounted for roughly two thirds of the families);

'I appreciate the time I don't have to worry about him [my son]'

'Giving me that extra couple of hours when you are 24/7 is magic'

'The enjoyment the kids get from going on the organised trips'

The remaining families largely received emotional support aimed directly at the parents, which didn't necessarily involve contact with the children; 
'I could talk to her she was very sympathetic'

'They have given us confidence'

'She was always there when you needed her, we could ring her up but we never did'

Families had a great deal of appreciation for the contribution and commitment of their volunteers. They appreciated 'time out' especially those whose children were particularly demanding and had behavioural or physical difficulties. Many also appreciated the understanding and empathy that volunteers gave them. Some found this had improved their own esteem and confidence. The relationship with a volunteer helped a number of parents overcome the isolation and uncertainty they felt coping with difficult children, without this it seems one or two of the parents would have been unable to continue caring for their children, indicating that the volunteers were providing much needed preventative support to vulnerable families and almost certainly reducing the likelihood of statutory intervention.

In relation to the key values of confidentiality, respect and understanding the volunteers scored extremely well on the Likert scales. Only one person was unsure about trusting the volunteer to respect confidences, and only one felt unsure about whether they were treated with respect. While eleven of the fourteen felt the volunteer understood their situation, three remained unsure. When asked what was the impact of having a volunteer upon their situation they were often quick to identify a specific area;

'We'd spent so long just ourselves and the boys, you get a bit stuck in a rut, then meeting her we sort of come out of ourselves, although we weren't trapped we felt like it sometimes.'

'Peter's [my son's] confidence is a hell of a lot better'

'Luke [my son] is having a medical in March to assess and diagnose him, this is all through Family Friends'

'Because if you need anything you don't get frightened to speak up for yourself'

'Yes I have gone back to work, I feel a lot better now that I have gone back to work, I was depressed, crying, I am a lot better now'

The table below indicates the different areas of life that are affected positively by the introduction of a Family Friends volunteer. The main area that is almost universally acknowledged is that having a volunteer allows parents to have some time to themselves. Significantly, $79 \%$ of the parents felt that having a volunteer has led to an improvement in their relationships with their children, sometimes this was achieved by helping parents broaden their understanding of a particular condition the child has, sometimes it was advice and guidance over discipline. The 'time-out' factor enabled parents to spend time with other children in the family, and improve the quality of relationship with children from whom they had had a break from. The $71 \%$ of parents who acknowledge an improvement in their self confidence due to having a volunteer is perhaps initially surprisingly high. But many parents spoke of feeling trapped, of internalising the child's behavioural problems and blaming themselves. In these situations volunteers have played a key role in being there to support, reassure, explain and encourage. The breakdown in self confidence and self esteem are major debilitating factors that can lead to a downward spiral of isolation. It is encouraging to see that this issue can be partly addressed by the use of volunteers. 


\begin{tabular}{|l|c|}
\hline \multicolumn{2}{|c|}{ Impact of Family Friends ( $=14)$} \\
\hline Helped me have more time for myself & $93 \%$ \\
\hline Helped Improve relationships with children & $79 \%$ \\
\hline Helped me feel more confident & $71 \%$ \\
\hline Helped improve my relationship with my partner & $43 \%$ \\
\hline Helped improve relationships with other agencies & $36 \%$ \\
\hline
\end{tabular}

The improvement in relationships with partners may not seem particularly impressive at 43\%, though it is worth noting that some relationships were not particularly close from the outset. The final category relationships with other agencies indicated a $36 \%$ improvement. For some families other agencies had a major role within theirs lives, whereas for others it was minimal. However, for the five families that acknowledged improvements, the volunteer seemed to be acting as an advocate making arrangements on behalf of the parent, or empowering the parent to feel equipped to engage with other agencies with whom they may otherwise had felt intimidated by. When asked what difference has it made to your life having a Family Friends volunteer a positive array of comments were provided by parents. The various types of support offered by the volunteers is reflected in the parents' responses. The fact that a relatively small input of time has meant so much to these parents perhaps illustrates the isolation and struggle that some feel in the face of some severe difficulties and challenges. It is also a reflection of the quality of input from volunteers. It raises issues about the networks of support within communities, families and friends for families in difficulty in the twenty-first century.

'We went through a really bad time in our lives ... it has made a difference. If we had not had the help it is hard to say what we would be like now. I don't think we would have been able to talk about our situation so freely, we can express things now'

'I don't have to dread him [my ex husband] coming to pick up the children. He doesn't bully me anymore. He doesn't stand in my door and won't go away anymore. It has definitely made a difference'

The appreciation of the support received and the friendships established inevitably raises difficulties for terminating a volunteer support for the family;

'We were tensed up before we had Family Friends ... things were getting out of hand ... who knows what would have happened ... I would like to thank Family Friends for the work they did for us and the help they gave us. Dr Todd referred us otherwise we would never have known about it. We wish we could have carried on'

'They need to get the right volunteer to the right family ... you need to know what the roles are and what to expect. Endings are awful, the volunteers are trained in endings but the families are not ... Endings need sorting out, we need to know the criteria for endings. I don't understand why the volunteer is being finished. ...

In terms of improvement families appreciated and valued the service they receive but wished they known about it earlier, or wished they could have more of it, and wished that it was able to extend beyond the age of eleven. They felt there was a shortage of volunteers, and wished that they didn't have to wait so long before receiving a volunteer. Other suggested included better matching, by for example; the availability of male volunteers; Welsh speaking volunteers; 
smokers; non smokers etc. The activities over the summer were valued and a number of families suggested there should be more events throughout the year.

The important issue of ending was raised by some of the families and this appears to be an issue worthy of serious consideration. It is clear that families develop close attachments and place a high value on volunteers. Boundaries need to be clarified to help volunteers, parents and the children understand the relationship and to be prepare for endings and transition. The relationship with the volunteers was widely seen by the families as distinctly different to the one with the Personal Social Services;

I have a lot of admiration for Family Friends. To social services it is just a job, to Family Friends it is more personal.'

'Not to be frightened of them, at first I thought they were social workers and going to take my kids away from me, they are not like that at all'

The volunteers were seen not as officials or professionals, but as friends of the family. This was particularly valued by the families some of whom had negative experiences with social work contact. This view is supported by other studies regarding families in need, such as Statham \& Holtermann (2004) who found that families criticised social workers for being too busy, inconsistent, not having the time to listen and not treating them as valued individuals. Interestingly these were the attributes most appreciated in the Family Friends volunteers. Many of the parents were impressed the way in which volunteers had been willing to become more than just a volunteer, making impromptu phone calls to see if they were okay, inviting them back to their homes, offering more assistance; one volunteer went on holiday with the family to provide extra support, though this was done outside the jurisdiction of Family Friends.

\section{Discussion}

As Harker notes" volunteer-run initiatives offer more than an occasional helping hand to support mainstream services" $(2003$, p.16)' and as the extracts from service users above highlight this is also the case for Family Friends. From the high level of users satisfaction in the support received, it is clear that this voluntary organisation plays a vital role in family support within the locality. The national and subsequently local political agendas have been dominated by 'early years' initiatives, often defined as five years or under. For example, 'Sure Start' now has 524 projects, although it is concerned with children up to the age of 14 (or 16 for a child with a disability), its focus has primarily been centred upon early years. This focus upon early years children has to some extent resulted in a lack of attention to the need to support families with children over 5 , and the families in this study would argue there is also a need to offer support beyond the age of eleven.

There are a number of key aspects of policy practice that this research has highlighted in relation to improving provision and practice, both for the organisation in question and arguably for other volunteer based services in England and Wales. These relate to five principle areas, namely; the recruitment and retention of volunteers, the advertising and promotion of the service, matching of needs, managing endings and sharing good practice.

i) Recruitment of volunteers.

Whilst, programmes such as the Millennium Volunteers have sought to challenge traditional stereotypical images of volunteers and the types of work that they engage in; 'volunteering' remains socially and culturally specific (Lukka and Ellis 2001). A number of families in this research commented upon the importance of choice and matching. There is a need for organisations to adopt a more proactive and targeted campaign to recruit volunteers from a more diverse background in relation to language, gender and age. This was most notable in the need for bilingual volunteers. The importance of linguistically sensitive practice and provision of services in a person's language of choice has been recognised (Davies 1994, Pugh \& Jones 1999, and Madoc-Jones \& Buchanan 2003). An increase in the number of male 
volunteers would also be beneficial and enable greater choice for service users than is currently available. The need to provide positive male contact to some children who may not have experienced positive male relationships, or where contact with males is fairly limited, was noted.

ii) Advertising and promotion of the service Many of the families wished they had heard of Family Friend earlier, however, promoting and advertising the service is problematic, due to the concern that it could result in the organisation becoming overwhelmed. Few service users had ever heard of the organisation before being referred, and some wished they'd have heard about the service much sooner. One of the recommendations from the research undertaken was that the organisation develops a leaflet to outline the services it provides and contact details. This would be particularly useful for those professionals referring service users for a service, and to the families themselves.

iii) Matching needs

As Harker notes 'free from the constraints of the usual professional boundaries, volunteer run schemes can be more flexible in combining elements of support' $(2003, p .16)$. The social isolation and specific needs of families means that they often require a service outside the 'regular' office hours of many statutory services. Volunteers can often provide this service, however, matching the volunteer with the family in terms of their characteristics/personality/hobbies and interests, as well as times they have available, are key factors. It is evident that for many respondents the matching process was in the majority of cases successful, and key to the formation of 'real' and significant relationships with their volunteer that may best be described as friendships. However, the size of the organisation meant that at times the 'notion' of matching was at times not always possible to achieve.

\section{iv) Managing endings}

Planning and preparing for endings can be a neglected area of social work practice. Similarly within this research it was identified that further work needs to be undertaken with children, their carers and volunteers to sensitively try and manage endings. Many of the volunteers are involved in regularly taking the children out for leisure based activities. Inevitably close relationships are developed. Offering involvement in summer play scheme or group activities to children and their families who no longer required a volunteer service is a good way of staying in touch and easing the transition. The impact of endings upon the volunteers who invest a lot of emotional support, the child/ren and carers needs to be carefully considered.

\section{Conclusion}

Family Friends has been providing a much needed service that could benefit by being replicated in other areas. The families under stress in this study clearly appreciate the respite offered by the provision of activities for their children, they particularly valued having somebody to provide what Gray described as 'emotional labour' (2002) - that is someone who was willing to listen, care, understand and befriend them. To some extent it could be argued that the volunteers are providing levels of practical and emotional support that may have previously been available in extended families and/or closely knit communities, but is now much harder to find. This support should not be exclusively focused upon early childhood but cover up until 16 years of age. The narratives from the families highlighted the level of stress and social isolation experienced by many of these families and illustrates the degree of suspicion and reluctance to engage with statutory agencies. Trained volunteers properly matched to families in need of support could have a significant role in the UK in enhancing family life and at the extreme preventing statutory intervention.

\section{Bibliography}

BASW (2002) Code of Ethics for Social Work, BASW, London

Buchanan, J., Parrott, L,. \& Williams, D (2002) 'Families in Need and the Impact of Volunteer Support', Wrecsam, North East Wales Institute 
Colton, M., Drury, C., and Williams, M . (1995) Children in Need: Definition, Identification and Support, British Journal of Social Work, Volume 25, pp.711-728.

Davies, E. (1994) They All Speak English Anyway. Cardiff: CCETSW.

Department of Health. (1998) Modernising social services: Promoting independence, improving protection, raising standards, London, The Stationery office

Frost, N \& Johnson, L (2000) 'Homestart and the Delivery of Family Support', Children and Society, Vol. 14, pp328-342

Gray, B (2002) 'Emotional labour and befriending in family support and child protection in Tower Hamlets', Child and Family Social Work, Vol.7, pp13-22

Harker, L (2003) 'Leading by Example', Community Care, 24-30 April 2003, p.14

Howarth, J. (ed) (2001)The child's world : assessing children in need, London, Jessica Kingsley

Home Start (2003) http://www.home-start.org.uk accessed on 01.06 .03

Jordan, B (2002) 'Family Support: Recent Trends in Social Policy, Representing Children, Vol 14 (4) 2002: 241-50

Krueger, R. A \& Casey, M. A. (2000) Focus Groups: A Practical Guide for Applied Research (3rd Edition), Sage, London

Lukka, P. \& Ellis, A (2001. 'An exclusive construct? Exploring different cultural concepts of volunteering' in Voluntary Action, 3 (3) 87-109 Autumn

McDonald, G. (1999) Social Work and it's Evaluation: A Methodological Dilemma? in Willams, F., Popay, J., and Oakley, A., Welfare Research: A Critical Review, UCL, London.

McDonald, G and Williamson, E. (2002) Against the odds: An evaluation of children and family support services, National Children's Bureau, London.

Madoc-Jones, I \& Buchanan, J, (2003) 'Welsh language, identity and probation practice: The context for change' in Probation Journal Special Issue: Discrimination and Diversity Vol. 50, No. 3 pp225-238

McGrath, $P$ (2001) 'Trained volunteers for families coping with a child with a life limiting condition, Child and Family Social Work, Vol, 6, pp23-29

Morris, K\& Shepherd, C (2000) 'Quality social work with children and families', Child and Family Social Work, Vol, 5 pp 168-176

National Statistics (2004) Wales its People: Welsh Language http://www.statistics.gov.uk/ accessed $28^{\text {th }}$ October 2004

Pugh R \& Jones, E.(1999) Language and Practice: Minority Language Provision within the Guardian Ad Litem Service, in British Journal of Social Work, Vol 29, pp529-545

Statham J \& Holtermann S (2004) 'The Effectiveness of Family Support Services' in Child and Family Social Work, Vol 9 pp153-166

Tunstill, J. (1997) Implementing the family support clauses of the 1989 Children Act in N. Parton (ed) Child protection and family Support: Tensions, contradictions and possibilities, London, Routledge.

Wardle, F., Lishman, J., \& Whalley, L.J (1999) 'Volunteers; making a difference'

Whitmore, E. (1994). To tell the truth: Working with oppressed groups in participatory approaches to inquiry. In P. Reason (Ed.), Particpation in Human Inquiry (82-98). Thousand Oaks, CA: Sage.

\section{This article was published in the Journal of Child \& Family Social Work:}

Parrott L, Buchanan J and Williams D (2006) Volunteers, Families and Children in Need: An Evaluation of Family Friends' Child \& Family Social Work, 2006, 11, pp147-155 Blackwell Publishing 